\title{
Resprouting Responses Dynamics of Schima superba Following a Severe Ice Storm in Early 2008 in Southern China: A Six-Year Study
}

\author{
Yonghui Cao ${ }^{1}$, Benzhi Zhou ${ }^{1, *}$, Xiaoming Wang ${ }^{1}$ and Lianhong $\mathrm{Gu}^{2}$ \\ 1 Research Institute of Subtropical of Forestry, Chinese Academy of Forestry, Fuyang 311400, Zhejiang, China; \\ fjcyh77@sina.com (Y.C.); wxm_fj@126.com (X.W.) \\ 2 Environmental Sciences Division, Oak Ridge National Laboratory, Oak Ridge, TN 37831, USA; \\ lianhong-gu@ornl.gov \\ * Correspondence: benzhi_zhou@126.com; Tel.: +86-5716-310-1053
}

Received: 15 December 2019; Accepted: 1 February 2020; Published: 6 February 2020

\begin{abstract}
In 2008, an unexpected and severe ice storm affected the forest of southern China. This storm caused damage in regeneration of an important dominant tree, Schima superba (Gugertree). To study this damage, we set up permanent monitoring plots in an ice-storm-damaged subtropical evergreen broad-leaved secondary forest dominated by S.superba in Jianglang Mountains, China. We surveyed the damage to all trees with a minimum basal diameter of $4 \mathrm{~cm}$ and monitored their growth for 6 consecutive years. We analyzed the degrees and types of damage for S.superba and their relationships with resprouting characteristics. The results revealed that the main damage types of S.superba were decapitation $(45.45 \%)$ and uprooting $(28.41 \%)$. The distribution percentage for both decapitated and uprooted trees were commonly highest in the range of 10-16 cm basal diameter (BD) size class. A great number of individuals sprouted vigorously after the storm. The mean total sprout number and sprout biomass per tree for S.superba varied by tree BD size class. During the first three years after the ice storm, decapitated trees of larger BD classes produced more sprouts per tree than trees of smaller BD classes. However, the opposite trend was seen in uprooted and leaning trees. There was a trade-off between the total number and length of the sprouts. The difference of mean sprouts number and biomass per tree with size class was mainly related to the damage types. As the recovery progressed since the ice storm, the number of sprouts and sprout biomass in uprooted trees was found mainly on the middle trunk sections of uprooted trees, but in the upper sections of decapitated trees. After six years, the mean number of sprouts per tree, on different parts of the tree and for the three types of damaged trees all declined; however, sprout biomass per tree all increased. The mean number of sprout and sprout biomass per tree on different sections for decapitated trees was always highest over time since the storm. Our study will help to provide data on resprouting ability to develop a predictive model for resprouting.
\end{abstract}

Keywords: ice-storm disaster; Schima superba; resprouting abiltiy; damage type; uprooted tree; decapitated tree; tree size

\section{Introduction}

Forests offset a substantial portion of anthropogenic carbon emissions [1]. Most global forests are shaped by disturbances, such as fire, hurricane, ice storm or herbivory, that damage or kill the aboveground biomass of plants [2]. With global climate change, the occurrence frequency and intensity of disturbance are likely to increase [3]. Impacts of disturbances on ecosystems are diverse. They affect the ecosystem's above- and belowground structure, species composition, biogeochemical processed, 
photosynthetic capacity and carbon pools [3]. However, the risk of natural disturbances makes future contribution of forests to the global terrestrial carbon cycle and carbon sink highly uncertain.

Ice storms are a large-scale natural disturbance event that can have significant influences on forest ecosystems and result in long-term changes to forest structure and composition [3]. Ice storms are common in East Asia [4] and in North America [5]. Ice storms exert their impact on forests mainly through physical forces. Because such weather conditions only happen in certain regions randomly and unpredictably, the impact of ice storms on forest ecosystems has not received appropriate attention, and so far very little is known in this field.

Resprouting has been regarded as a functional trait of plants and is an important life-history strategy in response to physical damage [6-10]. It allows individual plants to regenerate after damage to the aboveground biomass and persist in ecosystems with recurrent disturbances [11]. Thus, understanding the natural regeneration processes and plant responses to disturbances has practical applications in the restoration and management of forest vegetation [11]. However, the intraspecific variability in resprouting and the long-term resprouting response of different individuals to a similar disturbance have not been well documented [12].

In a few countries where ice storms significantly affect forest dynamics, case studies have been performed mostly on broad-leaved forests in Europe and North America [12-17]. However, little is known of woody plant resprouting in subtropical natural broad-leaved forest in Asia after such storms [18]. A rare opportunity to assess this dynamic response process of resprouting for damaged tree species during plant community succession in broad-leaved forests was provided by a massive ice storm that occurred in 2008 in China [4]. The 2008 ice storm struck southern and central China from 10 January to 6 February 2008 [4], a region of prominence for China's terrestrial carbon storage [19]. Forests suffered massive physical destruction [4]. Schima superba is a representative, widely distributed and dominant tree species in subtropical evergreen broad-leaved forests in China [20]. This species is valued commercially for its timber. It can also prevent the spread of wildfire and thus helps to protect forests. The heavy ice storm in 2008 brought disastrous damage to this species. However, no study has been done on resprouting dynamics of this species after disturbance events such as an ice storm; the production and vigor of new sprouts related to the damage types are unknown. This study focuses on the physiology of resprouting over time, and the variation in production of sprouts by tree size and damage category of $S$. superba plants.

\section{Materials and Methods}

\subsection{Study Site}

This research was conducted in the Jianglang Mountain Natural Reservation $\left(28^{\circ} 52^{\prime} 26^{\prime \prime} \mathrm{N}\right.$, $118^{\circ} 48^{\prime} 37^{\prime \prime}$ E), Jiang-Shan, Zhejiang province, China. The mountain topography ranges from $73 \mathrm{~m}$ above sea level to $1500 \mathrm{~m}$ at its highest point. The soil at the study site is mainly yellow loam, with thick layers of humus covered with woody debris and fallen leaves. Annual mean temperature was $17.1^{\circ} \mathrm{C}$ from 1950 to 2010 in this area. The highest temperature on record was $40.2{ }^{\circ} \mathrm{C}$ on July 31,1971 , and the lowest $-11.2^{\circ} \mathrm{C}$ on February 9, 1980. The mean number of frost-free days was 255 days. The annual mean precipitation during the same period was $1820 \mathrm{~mm}$. The area affected by the largest ice storm in January 2008 within the natural subtropical forest has a vegetation coverage rate of $67.1 \%$. Natural vegetation in the area includes evergreen broad-leaved forest, coniferous and broad-leaved mixed forest, coniferous forest and shrubs. Below $900 \mathrm{~m}$ sea level, the mountain is covered by forests of Schima superba (Gugertree), Pinus massoniana (Masson pine), Cunninghamia lanceolate (Chinese fir), Phyllostachys heterocycla cv. Pubescens (Moso bamboo), secondary shrubs and other vegetation types. Secondary forests are dominated by the following species: C. lanceolata, P. massoniana, Castanopsis sclerophylla (Hardleaf oatchestnut), Castanopsis fabri Hance, Cyclobalanopsis glauca (Thunberg) Oersted (Oriental white oak). The importance values of S.superba, C. lanceolata and P. massoniana are $>10.0$, and the rest of broad-leaved species is $<5.0$. The secondary forest selected for permanent plots survey and hit by 
the ice storms was at a height of 350-500 m above sea level, and on a slope of about 28 to 37 degrees, facing southwest to northwest. In this forest, the stem density averaged 2400/ha, stand basal area (BA) was $27.14 \mathrm{~m}^{2} /$ ha, with tree diameter at breast height ( $\mathrm{DBH}$ ) varying up to $25 \mathrm{~cm} \mathrm{DBH}$, and the stand DBH was $12.5 \mathrm{~cm}$ (see Figure 1).
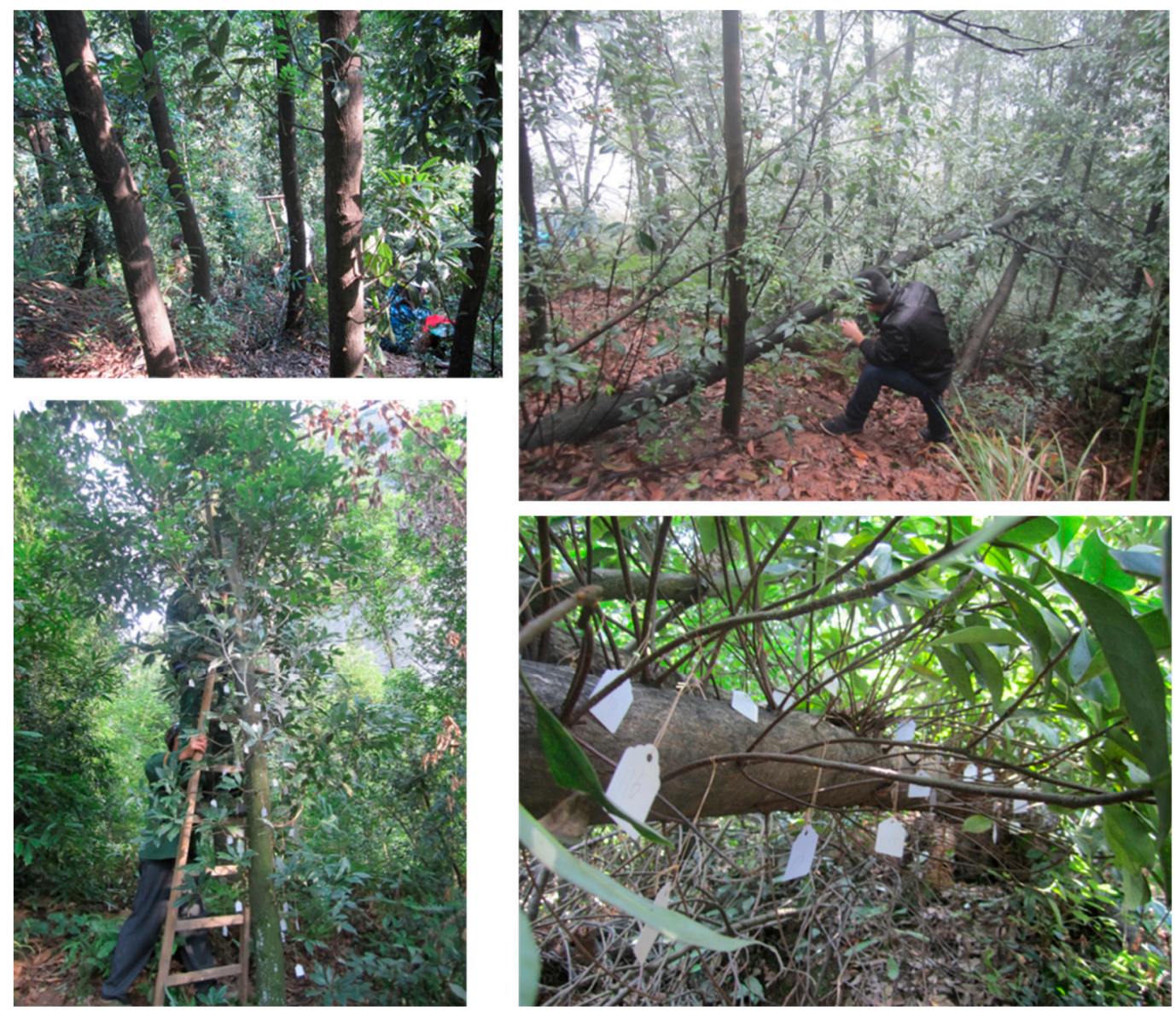

Figure 1. The field picture of Schima superba forest and the sprout measurement following the 2008 ice storm.

\subsection{Method}

\subsubsection{Tree Selection for Monitoring}

After the ice storm disaster that occurred in early 2008, six permanent sampling plots $(20 \mathrm{~m} \times 20 \mathrm{~m})$ were set. For all individuals with a minimum basal diameter of $4 \mathrm{~cm}$ in plots, the species name, damage type and grade, tilt angle of damaged trunk to its original upright position before the disaster, the diameter at breast height (DBH), base diameter (BD), tree height, crown width, slope position, aspect and other basic background information about the disaster were recorded. The comprehensive survey of forest identified that $S$. superba is the dominant damaged species in the disaster area.

The damage on S. superba trees was characterized into eight types: undamaged, dead, uprooting, leaning, bending, decapitation, branch-broken and stem-broken. Decapitation refers to trees decapitated with live crown removed from firmly standing trunks. Branches snapped or were still connected to the trunk. Uprooting refers to a root disc exposed and visible, one side of the root system still attached to soil, and with crown tops and branches showing different degrees of damage. Leaning refers to a trunk leaning toward the ground but not bent, with the root system still in the soil and the base of the trunk loosened from soil, where the root base is invisible, and the top of the tree is broken but still connected to the trunk. Bending refers to a trunk bent with the whole root system remaining in soil that was 
loosened or with no change and with branches and top of the tree broken or not affected. Dead refers to a root system completely detached from soil or no vital sign of the tree. Undamaged refers to no visible damage on trunk and branches. Stem-broken refers to a stem broken randomly below the crown.

In order to study the sprout-generation dynamic after the ice storm, fallen trees (uprooting and leaning trees) and those in the decapitated type were selected as targets for long-term monitoring. Thirty trees of different size classes $(\mathrm{DBH})$ in each damage type were tagged, and resprouting from those trees was recorded to quantify the regeneration dynamics of new sprouts.

\subsubsection{Sprouts Growth Measurement}

The sampled trees measured in mid-October 2008 were remeasured one time every year. After the ice storm, the sprouting of $S$. superba had begun immediately in late February for its biological trait. The total sprouts generated in the current disaster year have been surveyed for each sampled damaged trees in mid-October of 2008. Therefore, the first measurement of damaged S. superba already showed the sprouting activity. The sprouts measured included epicormic branches and sprouts boomed from the stem or stump basal. Beginning from the base of the trunk, the stem was divided into $1 \mathrm{~m}$ in length; within $1 \mathrm{~m}$ length, sprouts were numbered and listed for every year, and sprouts' basal diameter, sprouts' total growth and new increment in each recovery year were measured (see Figure 1). The location of the first sprout from the trunk base and the last sprout on the stem were also recorded. All the sprouts measured in a previous year were remeasured in November of each survey year, including sprout survival number, survival position, sprouts BD and length growth. New sprouts found in a survey year were also numbered and listed sequentially from the trunk base within $1 \mathrm{~m}$ section and measured according to the 2008 sample design.

\subsubsection{Sprout Biomass Measurement}

Two sample trees for each damaged type were selected for measuring the sprout biomass. All of the sprouts for each sample tree were cut and the sprout BD was recorded for each. All of the leaves and branches for each sprout were harvested and measured and their wet weight in the field was recorded. Then, 6 sprouts were selected randomly for each tree, and their leaves and branches were immediately brought back to the lab and put in the oven at $105^{\circ} \mathrm{C}$ for $2 \mathrm{~h}$ and then at $80{ }^{\circ} \mathrm{C}$ for $24 \mathrm{~h}$ to get constant dry weight. The model between $\mathrm{BD}$ of sprout, leaf dry weight $\left(\mathrm{W}_{\text {leaf }}\right)$ and branch dry weight $\left(W_{\text {branch }}\right)$ of each sprout was set up based on the data. The equations for estimating sprout leaf and branch biomass based on sprout basal diameter were $W_{\text {leaf }}=0.275 \times B^{\wedge} 1.7705$ and $W_{\text {branch }}$ $=0.0777 \times \mathrm{BD}^{\wedge} 2.5166$, respectively. The sprout biomass was the sum of leaf dry weight $\left(\mathrm{W}_{\text {leaf }}\right)$ and branch dry weight $\left(\mathrm{W}_{\text {branch }}\right)$ for sprout.

\subsubsection{Data Analysis}

Statistical analyses were conducted using Microsoft Excel 2003 v.11.0 (Microsoft Corporation, Washigton State, USA) and SPSS16.0 (SPSS Corporation, Chicago, USA). Analysis of variance tests were conducted to compare the number of new sprouts, their length growth and sprout survival number among different damage types. The $2 \mathrm{~cm}$ diameter classes were also used for analyzing the size distribution percentage of five damage types.

\section{Results}

\subsection{Damaged Types and Size Distribution of S.superba Tree Following Ice Storm}

In this research, of all the damaged trees of $S$. superba, the decapitation occurred with a highest proportion $(45.45 \% \pm 2.11 \%)$, followed by uprooted and leaning trees with a higher proportion $(28.41 \%$ $\pm 2.35 \%$ and $12.51 \% \pm 4.88 \%$, respectively), while the bending ones were the smallest proportion $(3.985 \%$ $\pm 0.92 \%)$ followed by the undamaged trees $(9.94 \% \pm 3.40 \%)$ (Figure 2$)$. Analysis of variance indicated 
that there is a statistically significant difference $(p<0.05)$ between the percentage of decapitated and uprooted individuals to total sample trees.

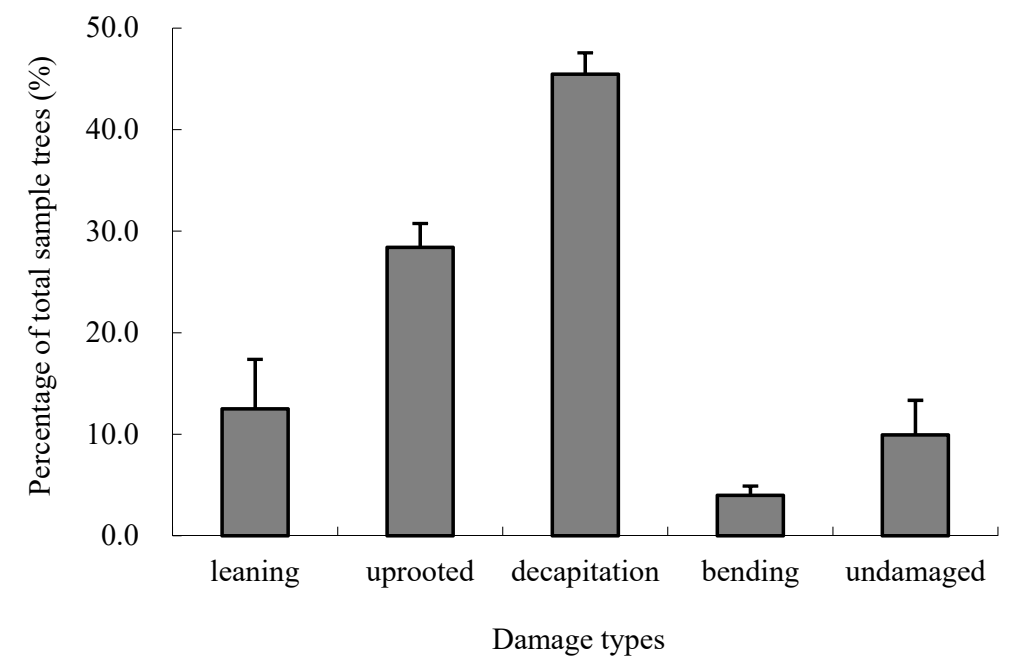

Figure 2. The distribution percentage of five damage types for S. superba total damaged trees in six sample plots following the 2008 ice storm.

The result showed that after this ice storm, sprouting trees were of varying BD sizes, ranging from a minimum of $4.8 \mathrm{~cm}$ for uprooted trees to maximum of $22.0 \mathrm{~cm}$ for decapitated trees (Figure 3). However, about $20.4 \%$ of the all sampled damaged trees were $\leq 10 \mathrm{~cm}$ in $\mathrm{BD}$, with $22.6 \%$ being $>15 \mathrm{~cm}$ and only $1.5 \%$ being $>20 \mathrm{~cm}$ (Figure 3 ).

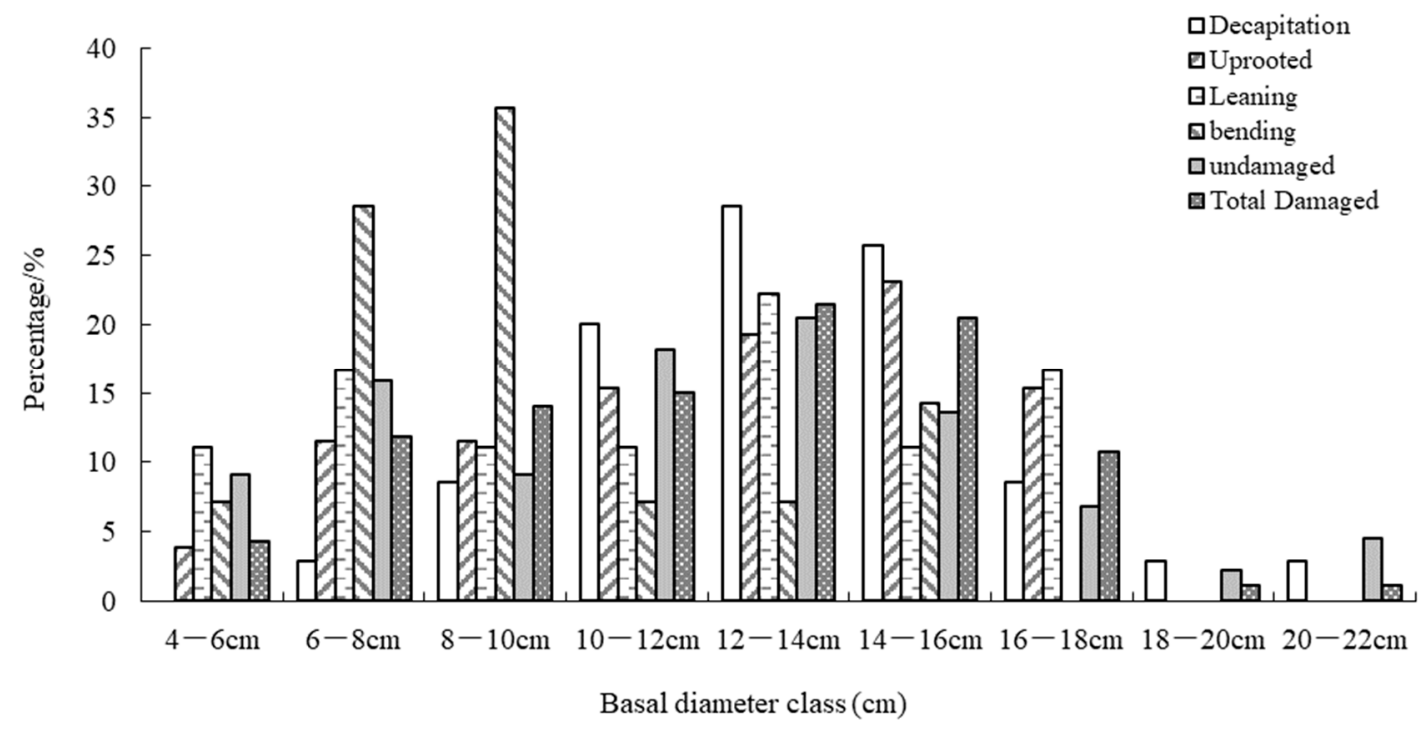

Figure 3. The size distribution percentage of five damage types in basal diameter classes in six sample plots following the 2008 ice storm.

The distribution percentage of the diameter class for both decapitated and uprooted trees was commonly highest in the range of 10-16 cm BD size class, while that of leaning trees was highest in the range of 12-14 cm BD size class. The bending trees were mainly distributed in the small BD size class of 6-10 cm, and it was in the 10-14 cm range for undamaged trees (Figure 3). 


\subsection{Resprouting on Damaged S. superba Trees}

\subsubsection{Variation of Sprouts Density}

A great number of individuals sprouted vigorously after the storm. The ratio of total sprout number to tree height (i.e., the height of the rest of the tree after damaging) in each recovery year was used to examine the differences on sprout density along the damaged tree stems among three types of damaged trees (Figure 4). The total sprout number per meter of height based on total tree height $(\mathrm{m})$ did not change from the beginning to the end of the sampling period for uprooted and leaning trees, while the value for decapitated trees was significantly higher during the first two years, then declined obviously and kept the same stable change trend with the other types of trees with increasing years (Figure 4). The number of sprouts per meter of height based on total tree height did not change for three types of damaged trees at year 6 after the storm.

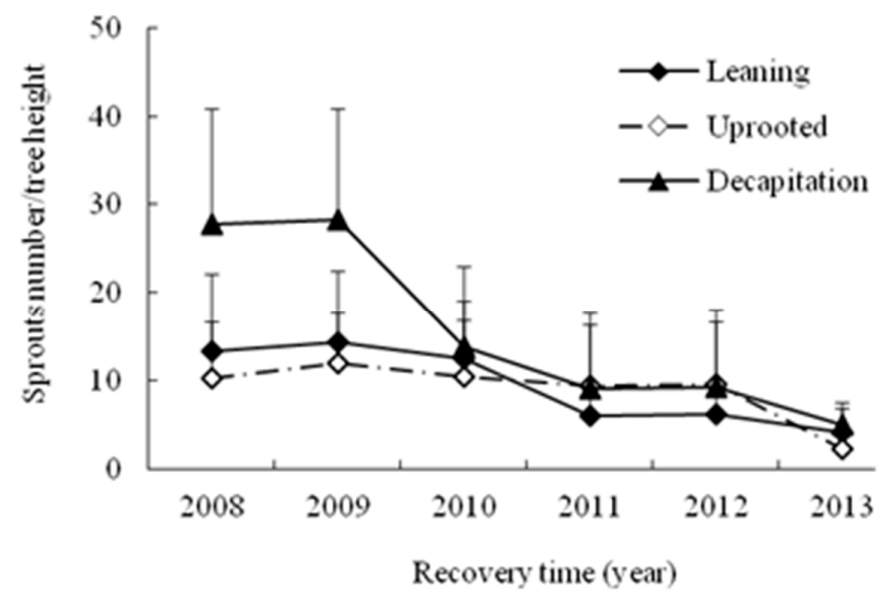

Figure 4. The annual change of total sprouts number per tree height for three damaged types of trees with increasing year.

\subsubsection{Temporal Variation in Sprout Annual Growth}

In the disaster year, the average annual new growth of an existing sprout was similar among three damaged types of trees (Figure 5). That of decapitated trees declined with increasing years during the first four years and then rose to 1.34 to 2.10 times that in the fifth and sixth year after the storm. This meant that the damaged trees commonly had less annual new growth of an existing sprout but produced a large number of sprouts after the storm.

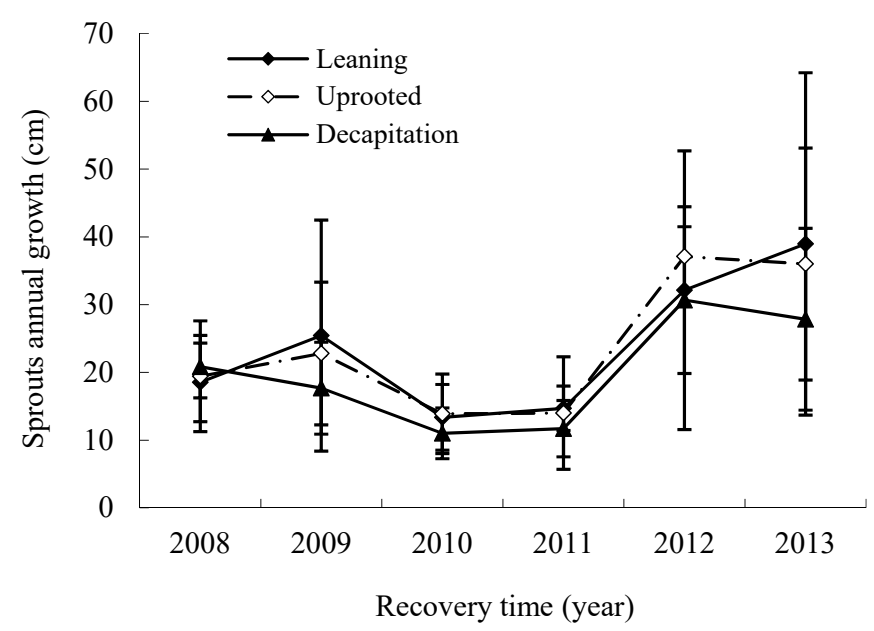

Figure 5. The annual change of sprouts new growth for three damaged types of trees. 
Based on annual increment, the annual new growth of sprouts of $S$. superba through the recovery years can be divided into three change phases: the early booming phase, the middle stable phase and the later accelerated growth phase, with the two years interval after this ice storm. Variance analysis shows that significant difference of the sprout new growth existed for each change phase during the disaster $(p<0.05)$.

\subsubsection{Temporal Variations in Sprout Biomass}

In this study, the effect of damage type on sprout vigor can be seen in the sprout biomass dynamics (Figure 6). For uprooted and decapitated trees, the mean sprout total biomass per tree exhibited a hump-shaped curve, rising over time to a maximum in year 4 and in year 5 after the storm, respectively, and then declining (Figure 6). In contrast, that of leaning trees kept a stable level during the recovery year. However, in year 6 after the storm, the variance of mean sprout biomass per tree among three damaged types of trees tended to be small.

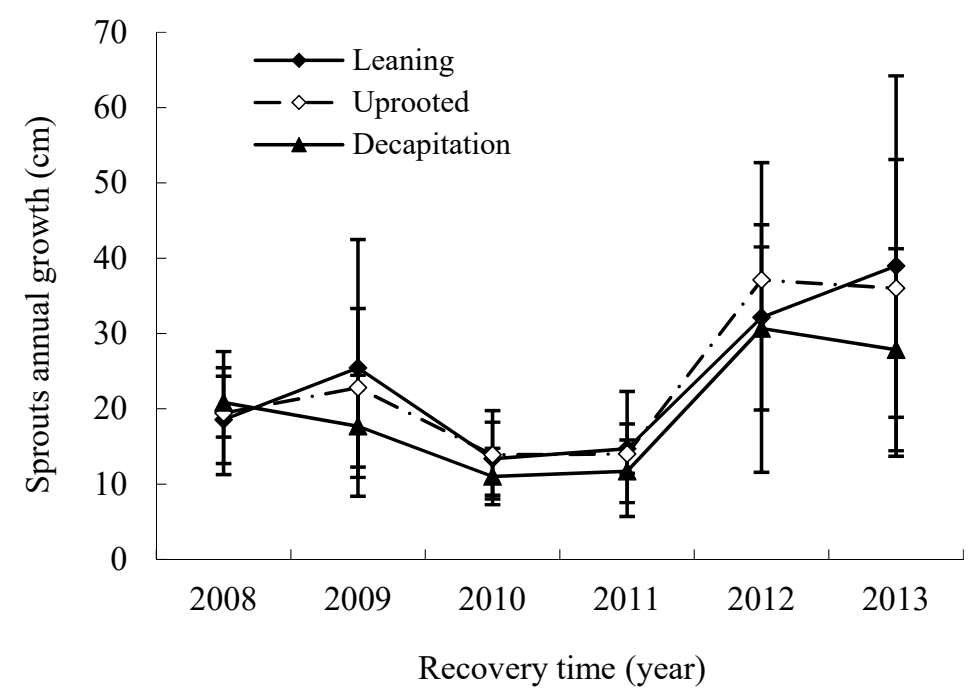

Figure 6. The annual change of mean total sprout biomass per tree for three damaged types.

\subsection{Sprout Distribution on Damaged Tree Stem}

\subsubsection{Sprout Number Distribution}

For the uprooted trees, the spatial distribution pattern of sprout number per tree on different stem sections was similar to a pyramid type in the second and the sixth year after the storm (Figure 7). On the contrary, data showed an inverted pyramid pattern for the decapitated trees and uniform distribution for leaning trees. The obvious difference of sprout number per tree on each section existed between the decapitated and uprooted or decapitated and leaning trees. After six growing seasons, sprouts on uprooted trees were mainly in the middle trunk sections, but sprouts on decapitated trees were in the upper sections of the stem.

From 2009 to 2013, the mean sprout number per trees on different sections for three types of damaged trees all declined (Figure 7). After six years, the decapitated trees had higher sprout numbers than uprooted or leaning trees, all at height levels $>1 \mathrm{~m}$ on the stem. 

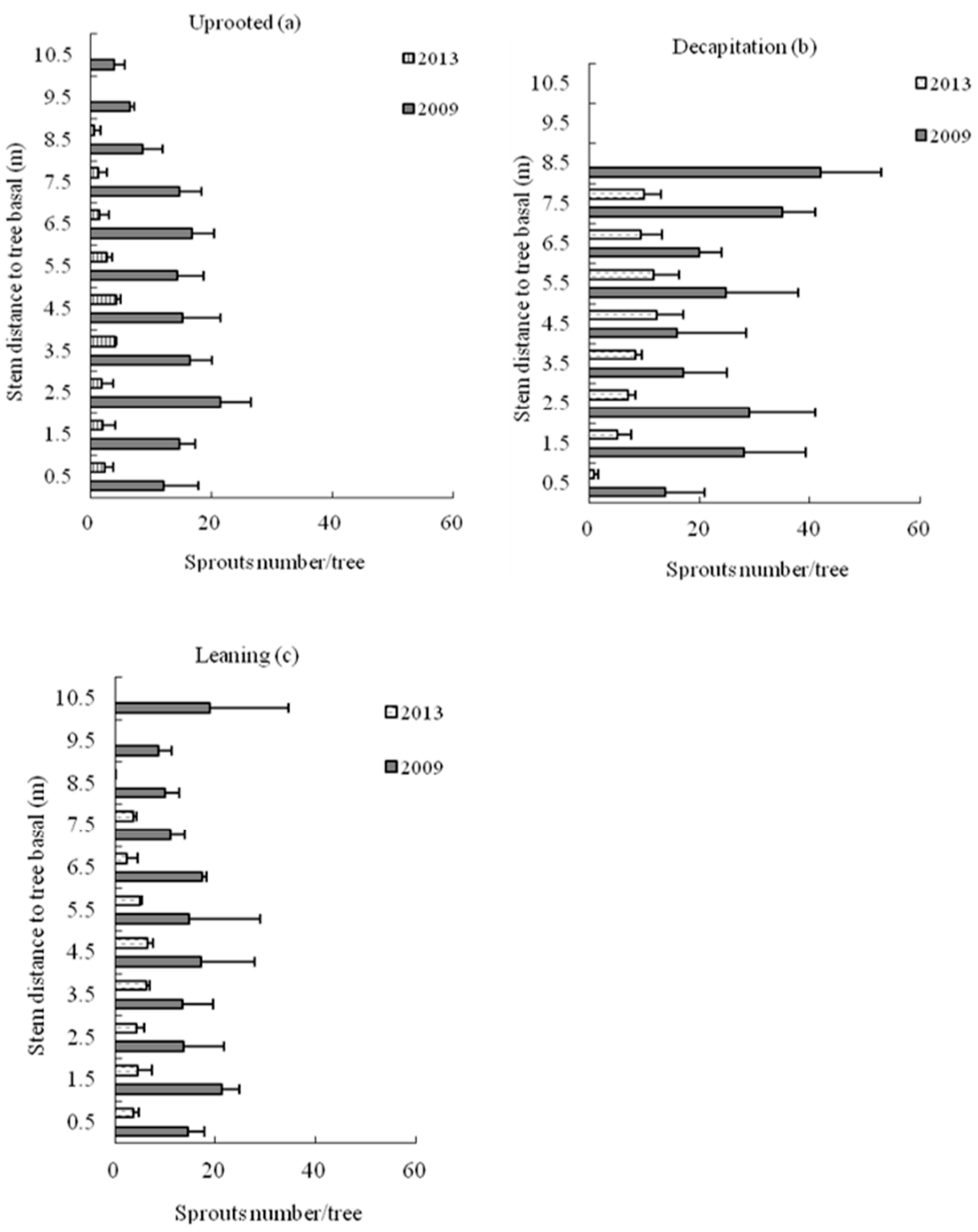

Figure 7. The sprout number per tree distribution on different section of tree stems for (a) uprooted, (b) decapitation and (c) leaning trees of S. superba in 2009 and 2013, respectively.

\subsubsection{Sprout Basal Diameter Distribution}

The mean sprout basal diameter along the stem for decapitated trees was larger on middle and upper trunk positions in the second and sixth year after the storm but was larger on basal stem section $<2 \mathrm{~m}$ distance to basal for uprooted and leaning trees (Figure 8).

During the recovery years, the mean sprout basal diameter on uprooted and leaning tree stem was significantly higher than that of decapitated ones at sections less than $1.5 \mathrm{~m}$ in distance to the trunk base, while it was lower than decapitated ones on the other tree stems section more than $2.5 \mathrm{~m}$ in distance to the trunk base. 

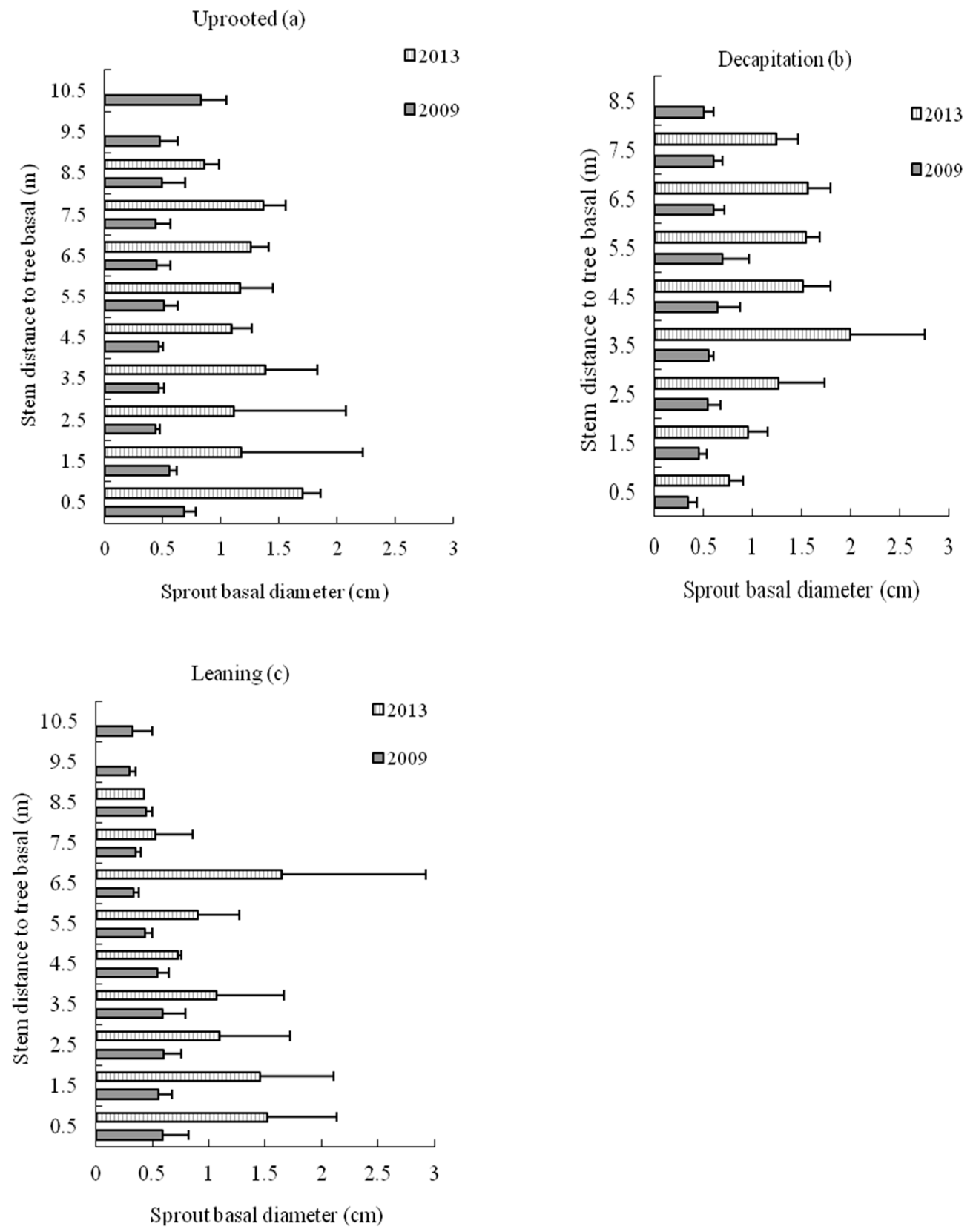

Figure 8. The sprout basal diameter distribution on stems (a) uprooted, (b) decapitation and (c) leaning trees of S. superba in 2009 and 2013, respectively.

\subsubsection{Sprout Biomass Distribution}

For three damaged types of trees, the mean sprout biomass on each tree stem section at an interval of $1.0 \mathrm{~m}$ all increased with the increasing recovery year after ice storm (Figure 9). The sprout biomass of decapitated tree was highest among three damaged types over time, and it was clearly visible six growing seasons after the storm. The sprout biomass was most apparent in the middle and upper parts for decapitated trees, and this distribution trend strengthened during the six years after the storm. This result showed that the sprout biomass production of $S$. superba also would be significantly affected by the damaged type. 


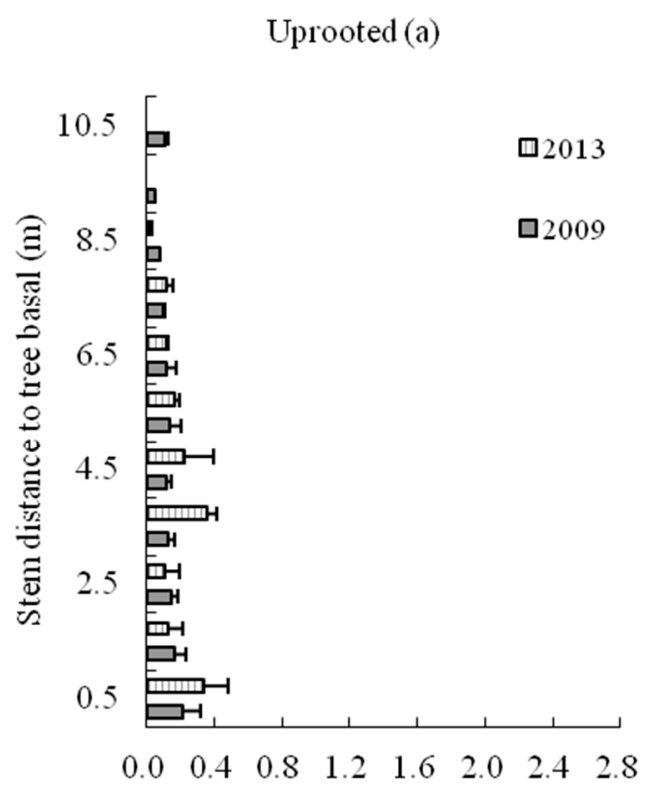

Sprout total biomass/tree $(\mathrm{kg})$

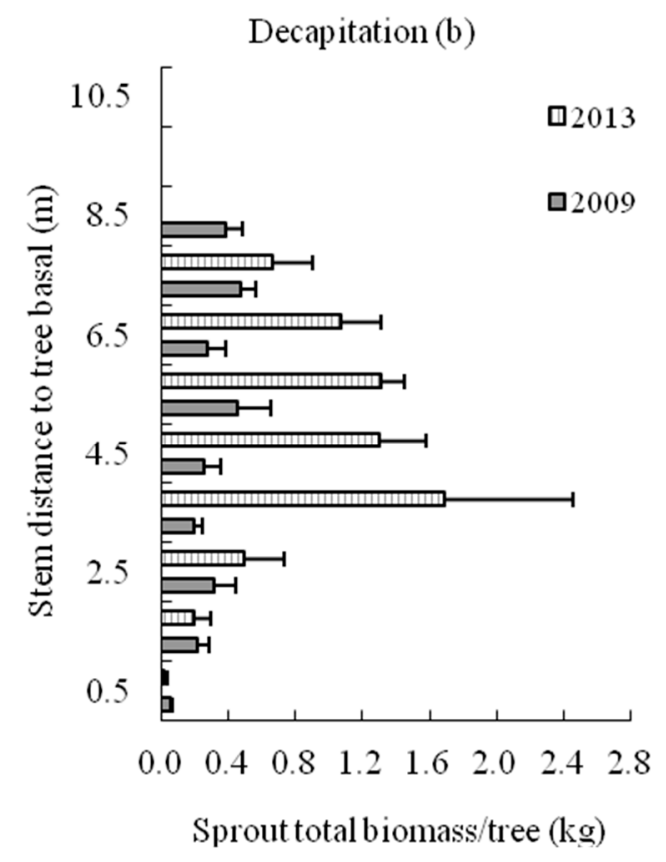

$\square 2013$

口2009

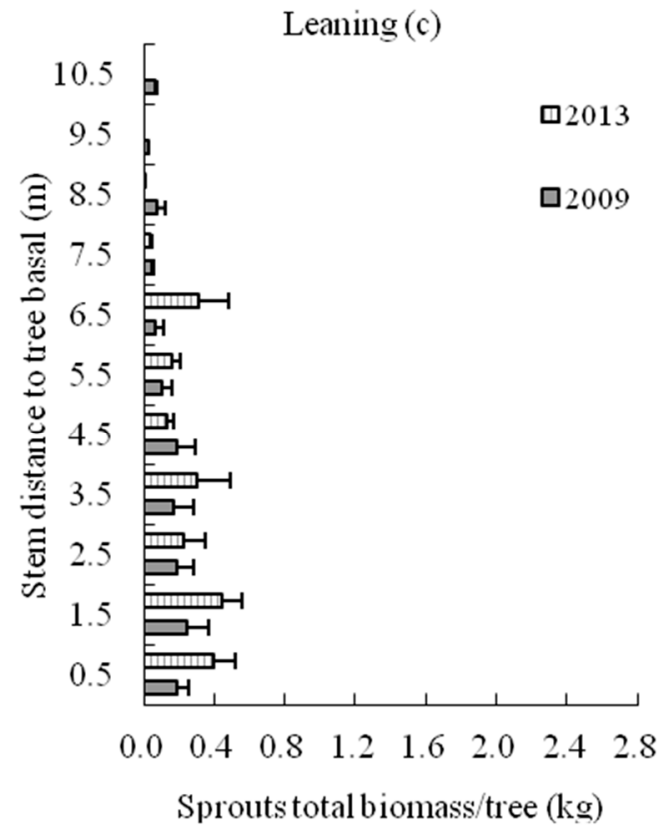

Figure 9. The sprout biomass distribution on (a) uprooted, (b) decapitation and (c) leaning tree stems of Schima superba in 2009 and 2013, respectively.

\subsection{Effect of Tree Size Class on Sprout Number, Biomass Distribution}

\subsubsection{Effect on Sprout Number}

The mean total sprout number per tree for S. superba varied by damage class and basal diameter (BD) (Figure 10). In the first three years after the storm, uprooted and leaning trees with small BD produced a larger number of sprouts than those with larger $\mathrm{BD}$, but after six years, the smaller trees had fewer sprouts than the larger trees. However, large decapitated trees produced more sprouts than smaller trees over time. 

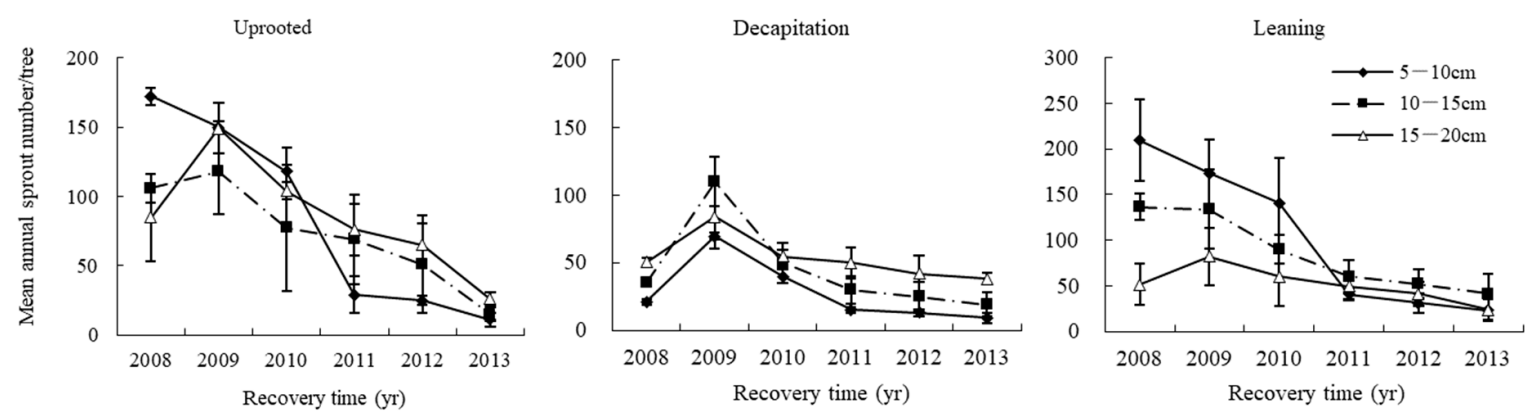

Figure 10. The annual dynamics of mean accumulative total sprout number for three diameter classes of uprooted, leaning and decapitation damaged trees.

Regardless of damaged types, the mean accumulative sprout number per tree for larger sizes of individuals of BD 10.1-20 cm exhibited a hump-shaped curve, with sprout number per tree rising during the first two years after the storm, then declining after that. The mean number of sprouts per tree in the smallest BD class of the uprooted and leaning damage classes declined from a high immediately after the storm through the sixth year after the storm. Finally, the mean total sprout number of all size-class trees kept a minimum stable level since the fourth recovery year.

\subsubsection{Effect on Sprout Biomass}

The mean sprout biomass of per tree stem for $S$. superba also varied by BD size class (Figure 11). Generally speaking, sprout biomass per tree was highest in the largest 15-20 cm BD class, especially in the 2010-2013 measurement years. In the sixth year after the storm, trends in sprout biomass by BD class were similar in the uprooted and decapitation damage classes. However, in the leaning tree damage class, sprout biomass in the largest BD class was much greater than in the two smaller BD classes (Figure 11).
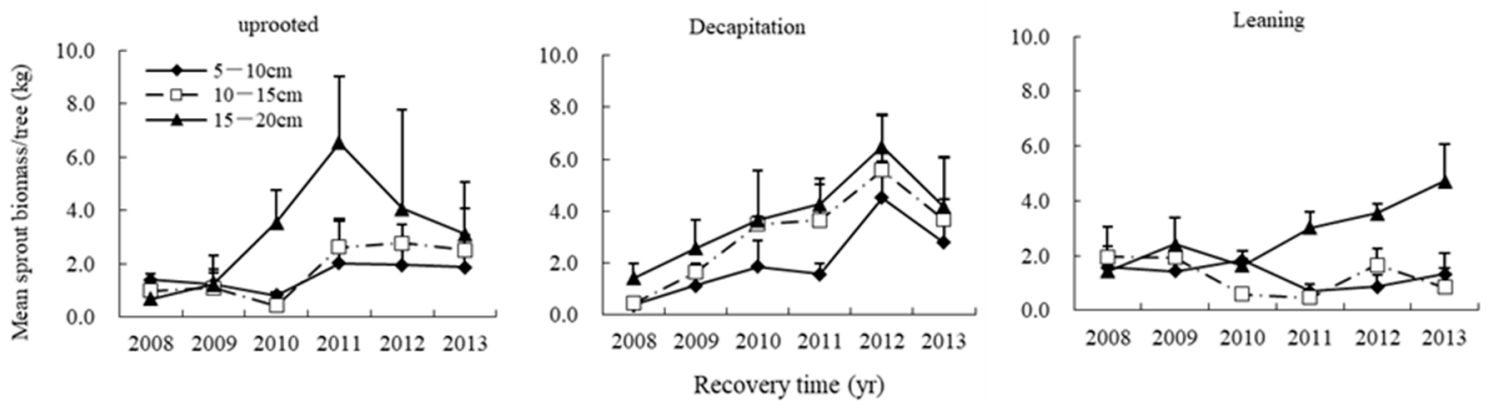

Figure 11. The annual dynamics of mean accumulative total sprout biomass for three diameter classes of uprooted, leaning and decapitation damaged trees.

3.5. Relationship Between DBH, Height of Damaged Tree, and Sprout Number per Tree, Total Sprout Biomass per Tree

Compared with the 2009 measurement two years after the storm, the 2010 measurement taken three years after the storm showed significant positive correlations of sprout number and biomass with DBH and height (Figures 12 and 13). The linear regression showed that tree DBH and height were less significant predictors of sprouting ability of the S. superba trees. Additionally, with the increasing recovery year, the effect of DBH of tree on sprout number per tree strengthened. 

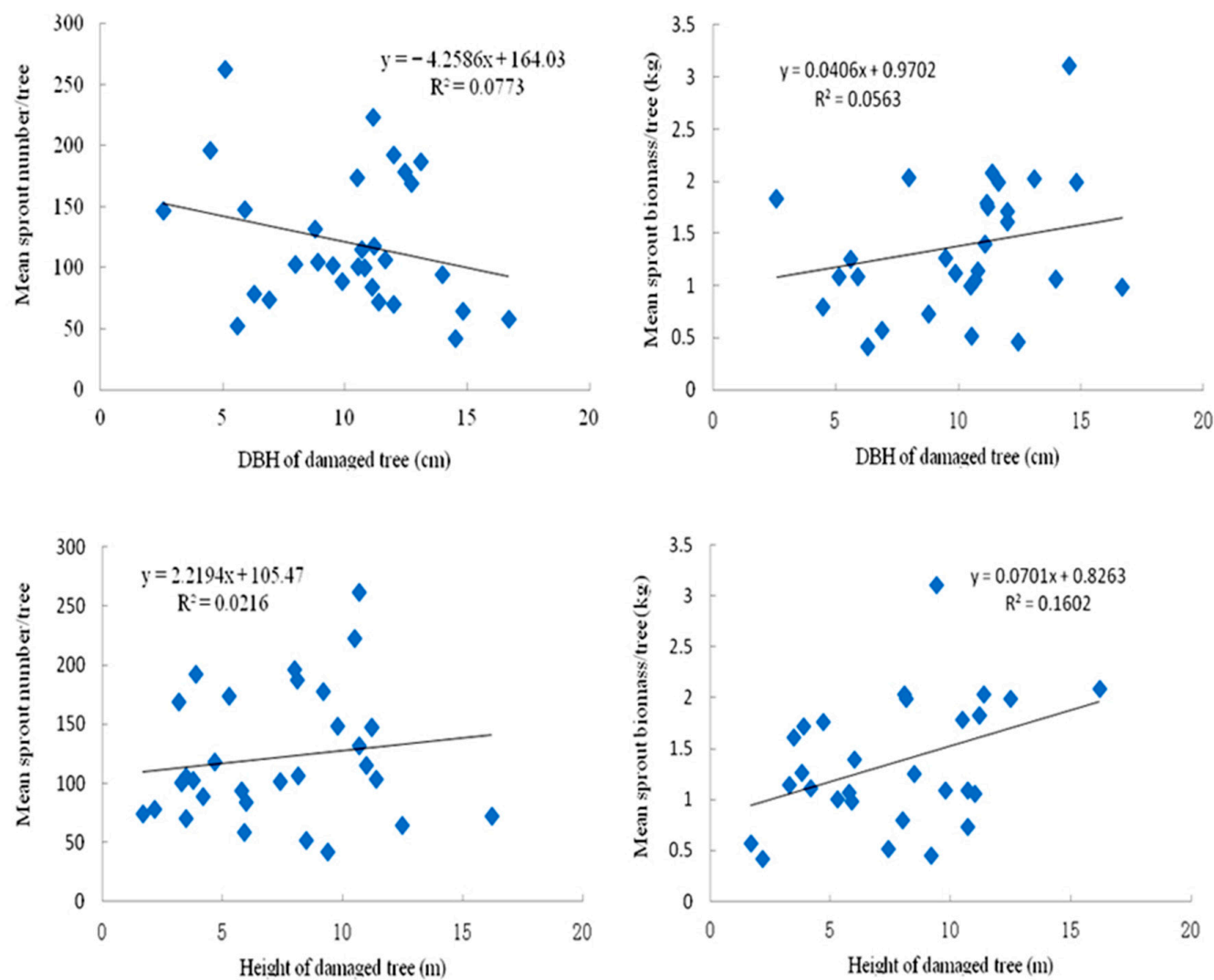

Figure 12. Regression analyses of diameter at breast height and height of sampled damaged tree on the sprout number/tree of all damaged types of trees in the 2009 year.
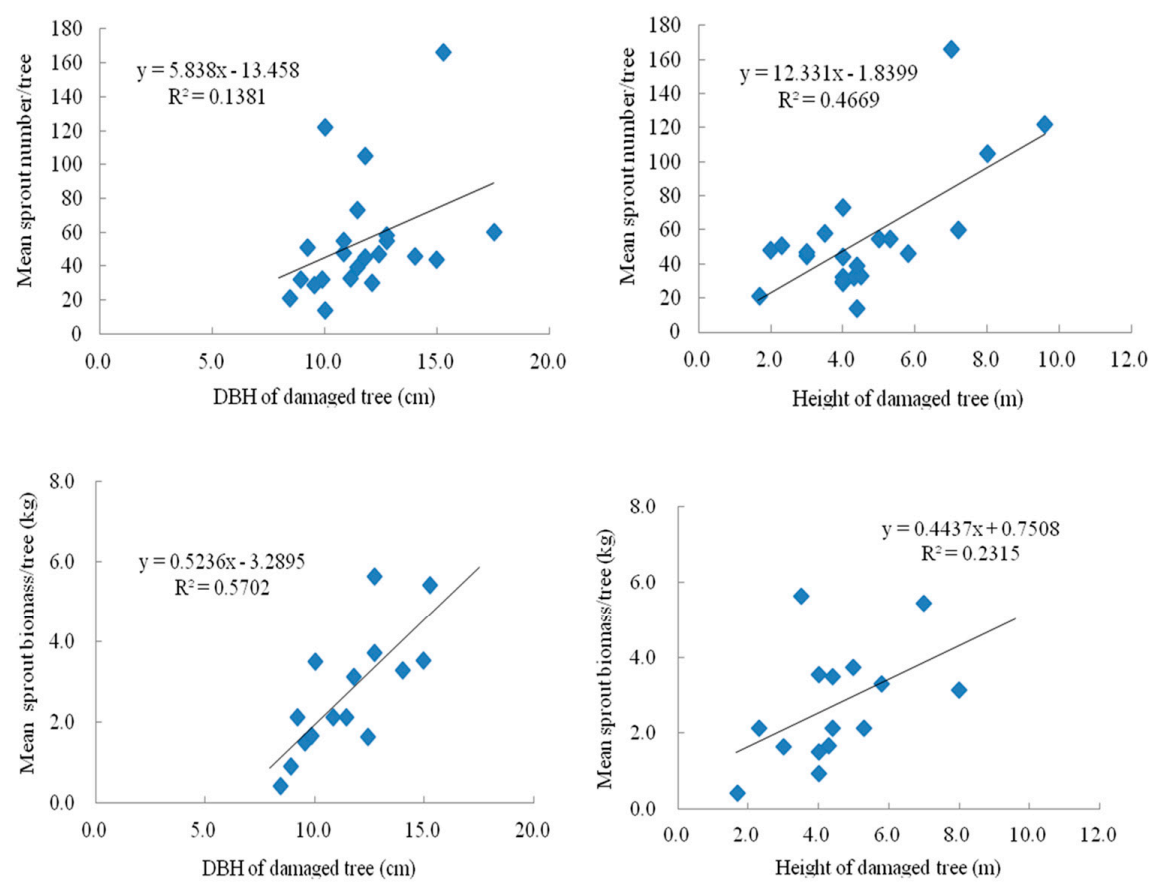

Figure 13. Regression analyses of diameter at breast height and height of sampled damaged tree on the sprout number/tree and total sprout biomass/tree of three damaged types trees, respectively in 2010 year. 


\section{Discussion}

The sprouting abilities compared among different sprouting species after being destroyed by different interference regimes have been widely reported in many studies [11,21-23]. However, detailed research into a single species' sprouting ability research is rare. Results from our study showed that the prolific sprouting ability of $S$. superba after a disturbance like ice storm damage in the subtropical forest of southeast China. Our research quantifies that effect after a storm event for S. superba. The prior research attempted to synthesize the global data on resprouting ability to develop the predictive model for resprouting [11,24,25], and our study for S.superba resprouting will serve this purpose undoubtedly. Our study also will help to advance our understanding of sprouting dynamics in a disturbance-driven ecosystem.

\subsection{Effect of Damage Type on Sprout Density and Sprout Generation Position}

Although some of the sprouts generated in the first year died slowly, the reemergence of a large number of sprouts in a short term increased the capacity of light interception in the crown, which would have compensated for the loss of carbon fixation capacity due to the disaster damage to the forest [26]. The epicormic branching within the crown led to crown rebuilding, resulting in high levels of tree survival and good poststorm diameter growth [25].

Brommit et al. [27] study showed that the sprouting regeneration ratio, i.e., the sprouting-to-damage ratio, is highly correlated with the degree of damage on trees. Loss of crown induces resprouting on a tree [27]. Subsequently, those factors play a key role in the locations on the tree where sprouts occur and the number of sprouts on those damaged trees. Branch breakage and stem snap are the most common injuries to residual trees in an ice storm-damaged forest [28]. Our research also showed that uprooted and decapitation were the two major damage types to $S$. superba after ice storm. Ice storms are a potential source of disturbance, and in examining the influence of tree size on damage type after ice storm strike in November 2014, Priebe et al. [29] found that in the Pacific Northwest, increasing diameter at breast height resulted in a significantly lower likelihood of bending but a significantly higher likelihood of crown loss [29]. Our study also showed that the distribution percentage of the diameter class for both decapitated and uprooted trees were commonly highest in the range of 10-16 cm BD size-class, while the bending trees mainly distributed in the small BD size-class of 6-10cm.

This study found that $S$. superba trees damaged by the ice storm all resprouted, but the production position, number and the size of sprouts depended on the damage type. After two years of recovery, uprooted trees produced more sprouts in the crown than those decapitated trees, especially in the lower and mid crown layers. The study suggested that during an ice storm, more distal sections will confer extra mechanical advantage to stems that need to grow quickly upwards and dominate and maintain their position in the canopy during the growing season [22].

Prior research proposed that reduction of the forest canopy by stem and branch breakage increases the amount of sun exposure on residual stems, favoring the development of respouts [30]. Differently from those, our study showed that sprout number distribution pattern on stem from base to upper was an inverted pyramid type for the S. superba decapitated trees, and with increasing years, the sprout number per tree were mainly distributed in the middle trunk sections for uprooted trees, while it was in the upper sections for decapitated trees.

Mwavu and Witkowski [21] pointed out that for a majority of woody species, resprouts are more likely to grow near the breaking point or at the trunk terminal [21]. According to Neke et al. [31], almost all tree species will resprout after harvest [31]. The interspecific difference may lie in whether those resprouts grow into many small auxiliary buds or a few big branches, and resprouts growing out of the trunk are more prone to terminal death than those emerging from the roots [31]. In this paper, it was found that on uprooted $S$. superba trees, the basal layer produced fewer sprouts than the middle layer. However, those emerging from the basal layer grew into bigger branches. Stokes et al. [22] also found that multistemming broadleaf species along the avalanche corridor had more numerous and shorter stems in severely disturbed zones [22]. In this paper, we found that there is 
a trade-off between sprout total number and sprout growth length. The damaged trees commonly had less annual new growth, although they produced a large number of sprouts after damage. It is beneficial for individuals to quickly mobilize sugars after physical damage; thus, resprouting can occur with an increasing rate [32]. In our research, the different damage types had an impact on the sprout development phase. In this study, during the first phase of recovery, a large number of resprouts for three damage types grew tall and fast, and they mainly relied on the carbohydrate reserves in stumps. Young leaves at the formation and expansion period become photosynthetic tissues [6]. Differently from that reported, the damaged S. superba trees commonly had less annual new growth, although they produced a large number of sprouts after being damaged in the first phase of recovery. During the second phase, the elongation growth of resprouts was very slow. Growth mainly relied on growing leaves for the supply of photosynthetic products as mobile reserves became less accessible. During the third phase, it had a larger annual new growth although it retained a small number of sprouts through six years of recovery.

\subsection{Tree Size Effect on Sprout ability}

The effect of plant size on resprouting vigour (i.e., the fact that larger plants resprouted more vigorously than smaller ones) may be explained by the positive correlation between size and the capacity of the belowground parts of the plant to mobilize resources after the disturbance; i.e., to use stored resources and uptake water and nutrients from the soil [33]. An extensive root system helps sustain the supply of nutrients and water; therefore, thick stumps generate more sprouts during recovery [34]. A study by Mwavu and Witkowski [21] found that the diameter at the base of trees has a significant positive correlation with the number of branches emerging from the stump [21]. According to Bellingham et al. [35], trees of $>10 \mathrm{~cm}$ DBH produce more sprouts than smaller trees [35]. Our results also emphasize the importance of plant size for initiating resprouting vigorously. Consistent with these early results, our study found that in the first three years after an ice storm, trees were prone to produce more sprouts per tree for the larger size-class than smaller ones of decapitated trees. However, it was easy to produce a large number of sprouts for smaller size-classes than larger ones for uprooted and leaning trees. This means that in our research, the change of mean sprout number per tree with size class was mainly related to the damage types. Mean sprout number per tree was significantly higher in 10.1-20 cm of DBH for decapitated trees during the recovery years after the storm. This closely compares with results from other studies [21], which reported higher sprouting ability among woody stumps of $\leq 16 \mathrm{~cm}$ and lower for $\geq 30.0 \mathrm{~cm}$ BD.

However, the correlation analysis found that in the early recovery year after ice storm, the tree size has no significant effect on the number of sprouts per tree, while with the increasing recovery year, the tree $\mathrm{DBH}$ was a significant positive predictor for the sprout number. This result was in accordance with the other early research conducted in American [36]. These results suggest that managers may want to consider tree size when planning for the risk of future ice storm events [22,29,32].

To a certain extent, sprout biomass responds to the plant resprouting vigor after a disturbance. Early studies showed that individuals that resprout can differ quantitatively in their resprouting vigor (e.g., resprouted biomass) [36]. Our result showed that the damage type was an important impact factor for the sprout biomass accumulation and its distribution on tree stem for S. superba. For the apical dominance of decapitated trees after a storm, they produced greater initial sprouting ability and their mean sprout biomass per tree recovered quickly through the first 4 years. This guaranteed that the decapitated trees recovered as soon as possible, making up the carbon loss after the elimination of aboveground biomass due to the ice storm. In contrast with the uprooted and leaning trees, the sprout biomass on the middle and upper stems increased with increasing recovery year for decapitated ones. The effect of tree DBH, sprout diameter and survived number of sprouts on sprout biomass production was significant. In this study, we found a positive linear regression existed between the mean sprout biomass per tree and DBH of all damaged trees. During the later recovery period, with the sprout growth, the tree $\mathrm{DBH}$ was a significant positive predictor for the sprout biomass per tree. 


\subsection{Restoration and Management of Forest After Disaster}

Dipesh et al. [37] simulated ice damage in southeastern Oklahoma to study the post-ice-damage effects and concluded that stands can recover from moderate ice storm damage without large loss in production [37]. Our study also supported this opinion. S. superba can tolerate some shade and regenerate at random, and it belongs to the sporadic regeneration type [20]. Based on those observations, during the recovery period after the disaster, the dominant species $S$. superba and other fallen trees produced many gaps in the forest, which had a potential influence on meeting the needs of light for the regeneration and growth of resprouts. In the disaster-affected area, the remains of uprooted trees help conserve soil quality and supplement soil carbon. Nevertheless, keeping those standing trees as a major vegetation composition should be the most important part in sustainable forestation in the disaster-affected forests.

Large resprouts on the top of uprooted or decapitated trees should not be trimmed, as they may eventually grow into big branches, while removal of smaller resprouting branches can reduce competition for resources. By adopting this strategy, we can selectively harvest wood or fuelwood while reducing the loss of forest production due to the death of fallen trees over time during the recovery period resultant from inappropriate management. It can also improve the microclimate for many other species, thus promoting regeneration and sustainability of forests.

\section{Conclusions}

After the 2008 unexpected severe ice storm occurred in southern China, the degrees and types of damage for $S$. superba and their relationships with resprouting characteristics were analyzed through the six-year study. The decapitation and uprooted were the main damage types. A great number of individuals sprouted vigorously after the storm. There was a trade-off between sprout total number and sprout growth length. The mean total sprout number and sprout biomass per tree for S. superba were of varying tree BD sizes. This change pattern was mainly related to the damage types. Over the year after storm, the mean sprout number per tree on different sections for three types of damaged trees all declined, while sprout biomass per tree all increased. This meant that $S$. superba trees can be recovered through six years by resprouting after ice storm. Our study also will help to provided data on resprouting ability to develop the predictive model for resprouting.

Author Contributions: Conceptualization, Y.C. and L.G.; methodology, Y.C.; software, Y.C.; validation, Y.C.; formal analysis, Y.C.; investigation, Y.C., X.W. and B.Z.; resources, Y.C.; data curation, Y.C.; writing-original draft preparation, Y.C.; writing-review and editing, Y.C. and L.G.; visualization, Y.C.; supervision, Y.C.; project administration, Y.C. and B.Z.; funding acquisition, Y.C. and B.Z. All authors have read and agreed to the published version of the manuscript.

Funding: This work was supported by the Special Fund for Basic Scientific Research from Central-level Non-profit Scientific Research Institutes of China (Grant No. CAFYBB2017MA004). This work was also supported by CFERN \& BEIJING TECHNO SOLUTIONS Award Funds on excellent academic achievements.

Acknowledgments: We thank Qianjiangyuan Forest Ecosystem Research Station for support of fieldwork. This work was guided on "Observation Methodology for Long-term Forest Ecosystem Research" of National Standards of the People's Republic of China (GB/T33027-2016).

Conflicts of Interest: The authors declare no conflicts of interest.

\section{References}

1. Pan, Y.; Birdsey, R.A.; Fang, J.; Houghton, R.; Kauppi, P.E.; Kurz, W.A.; Phillips, O.L.; Shvidenko, A.; Lewis, S.L.; Canadell, J.G.; et al. A large and persistent carbon sink in the world's forests. Science 2011, 333, 988-993. [CrossRef]

2. Lawes, M.J.; Clarke, P.J. Ecology of plant resprouting: populations to community responses in fire-prone ecosystems. Plant Ecol. 2011, 212, 1937-1943. [CrossRef] 
3. Sun, Y.; Gu, L.H.; Dickinson, R.E.; Zhou, B.Z. Forest greenness after the massive 2008 Chinese ice storm: integrated effects of natural processes and human intervention. Environ. Res. Lett. 2012, 7, 035702-035708. [CrossRef]

4. Zhou, B.Z.; Gu, L.H.; Ding, Y.H.; Shao, L.; Wu, Z.M.; Yang, X.S.; Li, C.Z.; Li, Z.C.; Wang, X.M.; Cao, Y.H.; et al. The great 2008 Chinese ice storm: its socioeconomic-ecological impact and sustainability lessons learned. $B$. Am. Meteorol. Soc. 2011, 92, 47-60. [CrossRef]

5. Changnon, S.A. Characteristics of ice storms in the United States. J. Appl. Meteorol. 2003, 42, 630-639. [CrossRef]

6. Poorter, L.; Kitajima, K.; Mercado, P.; Chubina, J.; Melgar, I.; Prins, H.H.T. Resprouting as a persistence strategy of tropical forest trees: Relations with carbohydrate storage and shade tolerance. Ecology 2010, 91, 2613-2627. [CrossRef]

7. Moreira, F.; Catry, F.; Duarte, I.; Acácio, V.; Silva, J. A conceptual model of sprouting responses in relation to fire damage: An example with cork oak (Quercus suber L.) trees in Southern Portugal. Plant Ecol. 2009, 201, 77-85. [CrossRef]

8. Clarke, P.J.; Lawes, M.J.; Midgley, J.J.; Lamont, B.B.; Ojeda, F.; Burrows, G.E.; Enright, N.J.; Knox, K.J.E. Resprouting as a key functional trait: how buds, protection and resources drive persistence after fire. New Phytol. 2013, 197, 19-35. [CrossRef]

9. Pausas, J.G.; Keeley, J.E. Epicormic resprouting in fire-prone ecosystems. Trends Plant Sci. 2017, 22, 22,1008-1015. [CrossRef]

10. Keyser, T.L. Resprouting by seedlings of four North American deciduous broadleaved tree species following experimental burning. OECOLOGIA 2019, 190, 207-218. [CrossRef]

11. Bond, W.J.; Midgley, J.J. Ecology of sprouting in woody plants: the persistence niche. Trends Ecol. Evol. 2001, 16, 45-51. [CrossRef]

12. Beaudet, M.; Brisson, J.; Messier, C.; Gravel, D. Effect of a major ice storm on understory light conditions in an old-growth Acer-Fagus forest: Pattern of recovery over seven years. Forest Ecol. Manag. 2007, 242, 553-557. [CrossRef]

13. Rhoads, A.G.; Hamburg, S.P.; Fahey, T.J.; Siccama, T.G.; Hane, E.N.; Battles, J.; Cogbill, C.; Randall, J.; Wilson, G. Effects of an intense ice storm on the structure of a northern hardwood forest. Can. J. For. Res. 2002, 32, 1763-1775. [CrossRef]

14. Yorks, T.E.; Adams, K.B. Ice storm impact and management implications for jack pine and pitch pine stands in New York, USA. Forest. Chron. 2005, 81, 502-515. [CrossRef]

15. Smolnik, M.; Hessl, A.; Colbert, J.J. Species-specific effects of a 1994 ice storm on radial tree growth in Delaware1. J. Torrey. Bot. Soc. 2006, 133, 577-584. [CrossRef]

16. Weeks, B.C.; Hamburg, S.P.; Vadeboncoeur, M.A. Ice storm effects on the canopy structure of a northern hardwood forest after 8 years. Can. J. For. Res. 2009, 39, 1475-1483. [CrossRef]

17. Rustad, L.E.; Campbell, J.L. A novel ice storm manipulation experiment in a northern hardwood forest. Can. J. For. Res. 2012, 42, 1810-1818. [CrossRef]

18. Wang, X.; Liu, H.; Gu, M.B.; Boucek, R.; Wu, Z.M.; Zhou, G.Y. Greater impacts from an extreme cold spell on tropical than temperate butterflies in southern China. Ecosphere 2016, 7, e01315. [CrossRef]

19. Piao, S.; Fang, J.; Ciais, P.; Peylin, P.; Huang, Y.; Sitch, S.; Wang, T. The carbon balance of terrestrial ecosystems in China. Nature 2009, 458, 1009-1013. [CrossRef]

20. Da, L.J.; Yang, Y.C.; Song, Y.C. Population structure and regeneration types of dominant species in an evergreen broadleaved forest in Tiantong national forest park, Zhejiang province, eastern China. Chin. J. Plant Ecol. 2004, 28, 376-384.

21. Mwavu, E.N.; Witkowski, E.T.F. Land-use and cover changes (1988-2002) around budongo forest reserve, NW Uganda: implications for forest and woodland sustainability. Land Degrad. Dev. 2008, 19, 606-622. [CrossRef]

22. Stokes, A.; Mine, F.X.; Mao, Z.; Brancheriau, L. Multi-stemming and mechanical traits ensure persistence of subalpine woody plants exposed to a disturbance gradient. J. Veg. Sci. 2012, 23, 325-338. [CrossRef]

23. Shibata, R.; Kurokawa, H.; Shibata, M.; Tanaka, H.; Lida, S.; Masaki, T.; Nakashizuka, T. Relationships between resprouting ability, species traits and resource allocation patterns in woody species in a temperate forest. Funct. Ecol. 2016, 30, 1205-1215. [CrossRef] 
24. Pausas, J.G.; Keeley, J.E. Evolutionary ecology of resprouting and seeding in fire-prone ecosystems. New Phytol. 2014, 204, 55-65. [CrossRef]

25. Nyland, R.D.; Dalton, J.L.; Allen, D.C.; Bevilacqua, E. Response of ice-damaged northern hardwood stands in northern New York. For. Chron. 2016, 92, 77-89. [CrossRef]

26. Casals, P.; Rios, A.I. Burning intensity and low light availability reduce resprouting ability and vigor of, Buxus sempervirens, L. after clearing. Sci. Total Environ. 2018, 627, 403-416. [CrossRef]

27. Brommit, A.G.; Charbonneau, N.; Contreras, T.A.; Fahrig, L. Crown loss and subsequent branch sprouting of forest trees in response to a major ice storm. J. Torrey Bot. Soc. 2004, 131, 169-176. [CrossRef]

28. Hopkin, A.; Fenech, A.; Liljalehto, H.; McLaughlin, D.; Williams, T. The Ontario Forest Health Data Co-Operative. Environ. Monit. Assess. 2001, 67, 131-139. [CrossRef]

29. Priebe, J.E.; Powers, M.D.; Cole, E.C. Species, tree size, and overstory environment affect likelihood of ice storm damage to understory trees in a mature Douglas-fir forest. Forest Ecol. Manag. 2018, 409, 777-788. [CrossRef]

30. Turcotte, R.M.; Elliott, T.R.; Fajvan, M.A.; Park, Y.L.; Snider, D.A.; Tobin, P.C. Effects of ice storm damage on hardwood survival and growth in Ohio. North. J. Appl. For. 2012, 29, 53-59. [CrossRef]

31. Neke, K.S.; Owen-Smith, N.; Witkowski, E.T.F. Comparative resprouting response of Savanna woody plant species following harvesting: the value of persistence. Forest Ecol. Manag. 2006, 232, 114-123. [CrossRef]

32. Nzunda, E.F.; Griffiths, M.E.; Lawes, M.J. Sprouting by remobilization of above-ground resources ensures persistence after disturbance of coastal dune forest trees. Funct. Ecol. 2008, 22, 577-582. [CrossRef]

33. Lloret, F.; López-Soria, L. Resprouting of Erica multiflora after experimental fire treatments. J. Veg. Sci. 2009, 4, 367-374. [CrossRef]

34. Luoga, E.J.; Witkowski, E.T.F.; Balkwill, K. Regeneration by coppicing (resprouting) of miombo (African savanna) trees in relation to land use. Forest Ecol. Manag. 2004, 189, 23-35. [CrossRef]

35. Bellingham, P.J.; Tanner, E.V.J.; Healey, J.R. Sprouting of trees in Jamaican montane forests, after a hurricane. J. Ecol. 1994, 82, 747-758. [CrossRef]

36. Paula, S.; Ojeda, F. Belowground starch consumption after recurrent severe disturbance in three resprouter species of the genus Erica. Botany 2009, 87, 253-259. [CrossRef]

37. Dipesh, K.C.; Will, R.E.; Hennessey, T.C.; Lynch, T.B.; Heinemann, R.A.; Holeman, R.T.; Wilson, D.E. Effects of simulated ice storm damage on midrotation loblolly pine stands. For. Sci. 2015, 61, 774-779. [CrossRef]

(C) 2020 by the authors. Licensee MDPI, Basel, Switzerland. This article is an open access article distributed under the terms and conditions of the Creative Commons Attribution (CC BY) license (http://creativecommons.org/licenses/by/4.0/). 